[ulm university - universitaet logo]

[uulm]

University UIm Ethics Committee 89069 UIm

Mr.

Prof. Dr. Harald Guendel

Clinic for Psychosomatic Medicine and

Psychotherapy

Am Hochstraess 8

$89081 \mathrm{UIm}$ [date stamp] September 26, 2011

\section{Ethics Committee}

Chairman: Prof. Dr. U. B. Brueckner Main office: Iris Seitz

Address:

Helmholtzstrasse 20 (Oberer Eselsberg) $89081 \mathrm{Ulm}$

Phone: $+49-(0) 731-500-22052$

Fax: $+49-(0) 731-500-22036$

Email: ethic-kommission@uni-ulm.de

http://www.uni-ulm.de/ethikkommission/

Direct line

Date

22052

09.26 .2011

$\mathrm{n} /$ To the members of the Ethics Committee of the University of UIm

Proposal Nr. 224/11 - The psychosomatic consultation at the workplace - a new model of care at the interface of company-supported mental health care and consultation-liaison psychosomatics

Dear Prof. Guendel,

On 09/05/2011, we started to negotiate your proposal. After all required adjustments were made on $09 / 23 / 2011$, we no longer find any ethical concerns in the implementation of your project.

The Ethics Committee of the University of Ulm approves the above referenced research.

According to the advisory function of the Ethics Committee, this assessment only pertains to the ethical and professional rules and assessment of the research concept, the proposed methods, the implementation and monitoring of the project as well as patient informed consent.

All medical and legal responsibility remains with the project manager and project staff.

- Changes in the research or the informed consent process must be approved by the Ethics Committee prior to implementation.

- The chairman of the Ethics Committee needs to be informed promptly in the event that serious, unexpected and related adverse events occur during the investigation which could affect the safety of study participants or the safe execution of the project.

- The Ethics Committee of the University of UIm presumes that non-medical project staff are committed to confidentiality.

- The Ethics Committee requires a timely notification about the project's completion and a report about its findings.

For the Ethics Committee of the University of UIm

[signature]

Prof. Dr. U. B. Brueckner

Chairman

Members of the Committee: Prof. Dr. U.B. Brückner (Chairman), Prof. Dr. J. Högel, prof. Dr. P. Kern, PD; Dr. M. Koelch, Dr. jur. H.-D. Lippert, Pastor E. Schaefer, Prof. Dr. H. Schrezenmeier, Mrs. Prof. Dr. J. Stingl, Mrs. Prof. Dr. H. Suger-Wiedeck 